\title{
Defect evolution during high temperature tension-tension fatigue of SLM AISi10Mg alloy by synchrotron tomography
}

\author{
Jianguang Bao ${ }^{\mathrm{a}^{*}, \mathrm{~b}}$, Shengchuan Wu ${ }^{\mathrm{c}^{*}, \mathrm{~d}}$, Philip J. Withers ${ }^{\mathrm{d}}$, Zhengkai Wu c, Fei Li a, e, \\ Yanan Fu ${ }^{\mathrm{f}}$, Wei Sun ${ }^{\mathrm{a}}$ \\ a Department of Mechanical, Material and Manufacturing Engineering, University of Nottingham, Nottingham, NG7 2RD, \\ United Kingdom \\ ${ }^{b}$ Aircraft Strength Research Institute, Xi'an, Shaanxi, 710065, China \\ c State Key Laboratory of Traction Power, Southwest Jiaotong University, Chengdu, 610031, China \\ ${ }^{d}$ Henry Royce Institute, Department of Materials, University of Manchester, Manchester, M13 9PL, United Kingdom \\ e Chengdu Aircraft Industrial (Group) CO., LTD, Chengdu, Sichuan, 610092, China \\ f Shanghai Synchrotron Radiation Facility, Shanghai Advanced Research Institute, Chinese Academy of Sciences, \\ Shanghai 201204, China
}

\section{A R T I C LE I N F O}

\section{Keywords:}

Defect evolution

Synchrotron radiation tomography

High temperature

AlSi10Mg alloys

Selective laser melting

\begin{abstract}
A B S T R A C T
Lack of fusion defects and porosity are inevitable characteristics of additive manufacturing and these are expected to play a key role in determining fatigue life and fatigue failure. This work followed damage accumulation under tension-tension cyclic loading at $250{ }^{\circ} \mathrm{C}$ in situ by time-lapse synchrotron radiation X-ray micro-computed tomography (SR- $\mu \mathrm{CT}$ ) for AlSi10Mg test-pieces, produced by selective laser melting (SLM) over their complete fatigue lives (ranging from 180 to 38,000 cycles). These samples were found to accumulate widespread plastic strain each cycle in common with ultralow cycle fatigue (UCLF) at low levels of triaxial constraint. The defects were found to elongate plastically at a rate approximately 10 times larger than their growth rate laterally.. This elongation behaviour at room and elevated temperature fatigue is proportional to the accumulated longitudinal strain increment each cycle. Rotation under the influence of shear is also observed for those defects close to the surface of samples. Some defect coalescence was observed, but final failure was found to be associated with the nucleation of a high density of secondary microvoids (occurring at eutectic Si platelets) that form just prior to failure and link up by microvoid coalescence. These steps may take up approximate $90 \%$ of the fatigue life. The final stage of cyclic plasticity occurs when the longitudinal strain exceeds $\sim 0.9$. Our results are in line with previous models of strain accumulation and defect growth under ULCF conditions.
\end{abstract}

\section{Introduction}

In recent years, aerospace manufacturers have been looking increasingly at additive manufacturing by selective laser melting (SLM) due to its potential for part simplification, fewer steps in the production process and greater design freedom [1-3]. With regards to the SLM process, AlSi10Mg is probably the most commonly used aluminium alloy, mainly due to its attractive solidification characteristics and relatively

\footnotetext{
* Corresponding authors.

E-mail addresses: wusc@swjtu.edu.cn (S.C.Wu), jianguang.bao@nottingham.ac.uk (J. Bao).
} 
low coefficient of thermal expansion [4]. However, the SLM process has a tendency to generate internal defects during solidification as a result of lack of fusion, shrinkage and/or trapped gas. Unsurprisingly, their presence is detrimental to mechanical performance, especially in the case of fatigue during service life [5-7].

Most of the research to date has focused on high cycle fatigue (HCF) in which the defects act as crack nucleation sites [8-11] and a number of studies looking at the HCF of SLM AlSi10Mg alloy parts are beginning to emerge [12-15]. While the 3D shape of the defect influences the local stress concentration [9], the defect size is the first order parameter that controls the fatigue limit [12]. Further, defects at the surface have been found to be more potent in terms of initiating fatigue cracks than those within the interior $[8,16,17]$. Larrosa et al. [13] found that for SLM parts many of the pores were pancake-shaped such that fatigue life was shorter for samples tested parallel to the build direction rather than normal to it because the pancakes tended to lie in the plane of the additive manufacturing (AM) layers.

In comparison to HCF, the effect of defects introduced by AM on low cycle fatigue (LCF) is relatively unexplored. In such cases significant plasticity is expected to occur around defects with those at the surface likely to be less potent due to the lower triaxial constraint compared to the bulk. For SLM AlSi10Mg alloy parts, the effect of defects on damage evolution under LCF has received very little attention, especially at elevated temperature. In this respect it is noteworthy that the effect of temperature is pronounced for cast aluminium alloys; Dezecot et al [18] found that for the LCF of cast AlSi7Cu3Mg alloy (close to ASTM A319) at $250{ }^{\circ} \mathrm{C}$, high local plastic strain develops near large micro shrinkage pores with complex shapes and that crack initiation occurs when the matrix ligament between the pore and the damaged hard particles is broken. For a cast $\mathrm{AlSi} 10 \mathrm{Mg}(\mathrm{Cu})$ alloy test-pieces, Cai et al [19] simply characterised the LCF fatigue 
life at $100{ }^{\circ} \mathrm{C}$ and $250{ }^{\circ} \mathrm{C}$ finding that the critical defects were casting defects, largely shrinkage pores located at, or near, the surface of specimens. While the defect behaviour during fatigue is similar for cast and SLM produced parts at room temperature [20], no elevated temperature studies have been undertaken for SLM parts. As a result it is important to investigate the LCF response of SLM AlSi10Mg alloy parts at elevated temperature to ensure their safe lifing, especially given their propensity for SLM defects.

X-ray micro-computed tomography $(\mu \mathrm{CT})$ makes it possible to visualize and quantify defects at the micron scale in three dimensions (3D) and to follow their behaviour during fatigue [21]. In particular the intensity of synchrotron radiation X-ray sources make synchrotron X-ray micro-computed tomography (SR- $\mu \mathrm{CT}$ ) particularly well suited to time-lapse experiments [22]. Over the last two decades, time-lapse SR- $\mu$ CT has shed light on the micro-mechanisms and sequence of damage accumulation across many metallic systems and loading conditions [23-26]. In view of their propensity for included defects, $\mu \mathrm{CT}$ is finding increasing application in the study of the fatigue of $\mathrm{AM}$ parts $[17,20,27,28]$. However, to date the majority of in situ fatigue tests studies have focused on HCF at room temperature, although recently high temperature HCF fatigue studies have also been carried out $[18,29,30]$.

To the authors' knowledge, this work is the first to report on fatigue damage accumulation arising from internal defects in additively manufactured material during tension-tension cycling at high temperature. Critical to this is the use of SR- $\mu \mathrm{CT}$ monitoring to track defect evolution and damage accumulation. Under these conditions we see many similarities with the growth and coalescence of defects seen previously for steels deformed under ultra low cycle fatigue (ULCF) [31]. Finally in the light of this new 
evidence, the damage mechanisms of SLM AlSi10Mg alloy under high stress elevated temperature fatigue are discussed.

\section{Experimental methods}

\subsection{Material and test specimens}

The AlSi10Mg powder particles used for SLM were distributed between $15 \mu \mathrm{m}-40$ $\mu \mathrm{m}$ in diameter (based on the sieving method) and the chemical composition is shown in Table 1. To ensure identical processing conditions, all the investigated AlSi10Mg alloy parts were produced on the same SLM machine, a BLT S310 (Xi'an Bright Laser Technologies Co., Ltd), which has a $500 \mathrm{~W}$ fibre laser with the beam quality $\mathrm{M}^{2}$ up to 1.1 and has a build area of $250 \times 250 \times 400 \mathrm{~mm}^{3}$. The build chamber was flooded with Argon gas during the fabrication process, thereby ensuring a protective atmosphere with an oxygen content $<100 \mathrm{ppm}$. No platform preheating was used for any of the batches. The following parameters were applied: laser beam power: $360 \mathrm{~W}-400 \mathrm{~W}$, layer thickness: $0.05 \mathrm{~mm}$, laser scanning speed: $1200 \mathrm{~mm} / \mathrm{s}-1500 \mathrm{~mm} / \mathrm{s}$, and laser scanline spacing: $0.13 \mathrm{~mm}-0.16 \mathrm{~mm}$. To relieve the residual stresses, thermal stress relief was subsequently performed at $300^{\circ} \mathrm{C}$ for $2 \mathrm{~h}$, prior to removing specimens from the support structures.

Table 1

Chemical composition of the AlSi10Mg powder.

\begin{tabular}{cccccccc}
\hline $\begin{array}{c}\text { Alloying } \\
\text { element }\end{array}$ & $\mathbf{S i}$ & $\mathbf{M g}$ & $\mathbf{F e}$ & $\mathbf{C u}$ & Mn & $\begin{array}{c}\text { Trace } \\
\text { elements }\end{array}$ & Al \\
\hline wt $\%$ & $9.0-11.0$ & $0.4-0.6$ & $\leq 2.0$ & $\leq 0.6$ & $\leq 0.35$ & 0.25 & Balance \\
\hline
\end{tabular}

The coordinate system used in this paper is illustrated in Fig. 1a where the build direction is defined as the Z-axis, the axial direction of the test-pieces is defined as the Xaxis and the transverse direction as the Y-axis. As a result, the loading direction is perpendicular to the build direction. Fig. 1b shows representative optical micrographs depicting overlapped melting pools having a 'fish scale' morphology of boundaries. In 
order to identify suitable fatigue test conditions, the tensile properties of the as-built material were determined prior to the in situ fatigue tests, see Table 2. A bespoke, high temperature fatigue test rig (see section 2.2) was employed on a SR- $\mu$ CT beamline for the in situ observations. In order to resolve at the micron scale, only miniature specimens could be studied. Cylindrical fatigue specimens with a scaled down gauge diameter of $1.4 \mathrm{~mm}$ were initially designed to the specification given by ISO 12106(2017E), however the gauge length was shortened from $2.8 \mathrm{~mm}$ to $2.4 \mathrm{~mm}$ to ensure the whole gauge length was accommodated within the high contrast field of view for SR- $\mu$ CT along all fatigue cycles.

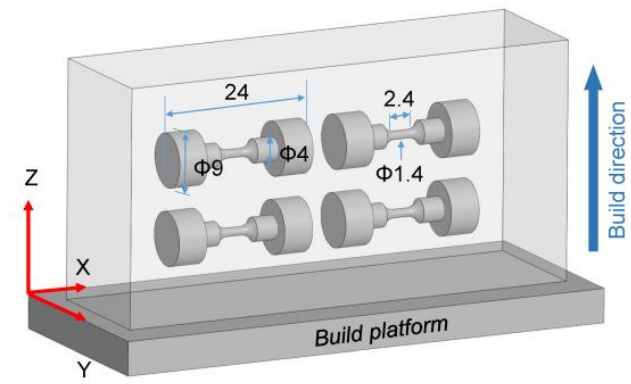

(a)

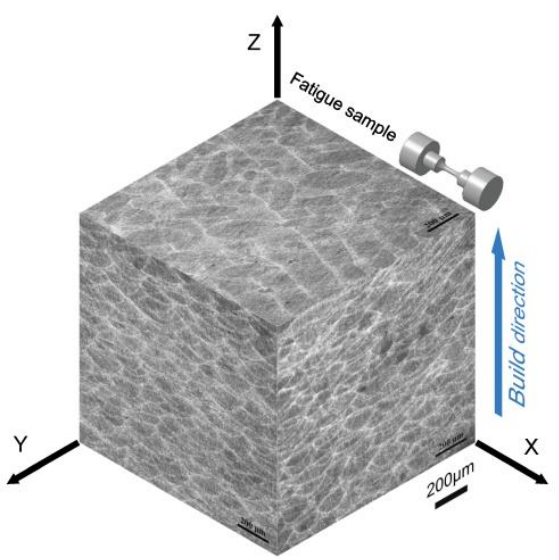

(b)

Fig. 1. Schematics showing (a) the SLM block and the fatigue test-piece extraction (dimensions in $\mathrm{mm}$ ) and (b) 3D reconstruction comprising optical micrographs of the as-received material after surface polishing and etching.

Table 2

Basic mechanical properties of the SLM samples.

\begin{tabular}{ccccc}
\hline Temp $\left({ }^{\circ} \mathbf{C}\right)$ & E $[\mathrm{GPa}]$ & $\sigma_{y 0.2}[\mathrm{MPa}]$ & UTS [MPa] & Elongation [\%] \\
\hline $\mathbf{R T}$ & 61 & 208 & 300 & 18 \\
$\mathbf{2 5 0}$ & 50 & 101 & 113 & 29 \\
\hline
\end{tabular}

\subsection{Synchrotron radiation X-ray micro-computed tomography}

Beamtime access limitations and the complexities of installing a thermomechanical testing rig on a synchrotron beamline mean that high temperature fatigue testing is challenging to undertake. Consequently only a few studies have been reported to date 
$[18,29,30]$. In the current work, a $14 \mathrm{~kg}$ bespoke in situ fatigue test rig was designed and built specially for high-resolution SR- $\mu \mathrm{CT}$, see Figs. 2 . The loading and rotation axis is vertical, and the waist of the cell consists of a polymethyl methacrylate (PMMA) window ( $3 \mathrm{~mm}$ thickness, $5 \mathrm{~mm}$ height), which allows X-rays to illuminate the sample and the attenuated beam to pass through to an X-ray area detector. The sample is held by high temperature resistance grips in the centre of the high temperature cell (diameter $\sim 16$ $\mathrm{cm}$ ). Heating is provided by a temperature actuation module (HCP421G-CUST) using two resistance wire heating plates which are located in the upper and lower grips. With a resistance temperature detector inside the oven, the rig is a closed loop temperature control system which can apply fatigue loading at temperatures ranging from $-190^{\circ} \mathrm{C}$ $600^{\circ} \mathrm{C}$. The fatigue operation incorporates a simple servo motor driven cam which can apply sine wave loading. The operating frequency is $0.1 \mathrm{~Hz}-20 \mathrm{~Hz}$ and the peak force is $1000 \mathrm{~N}$.

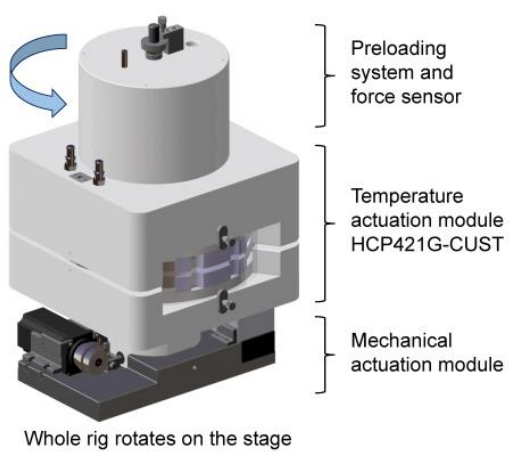

(a)

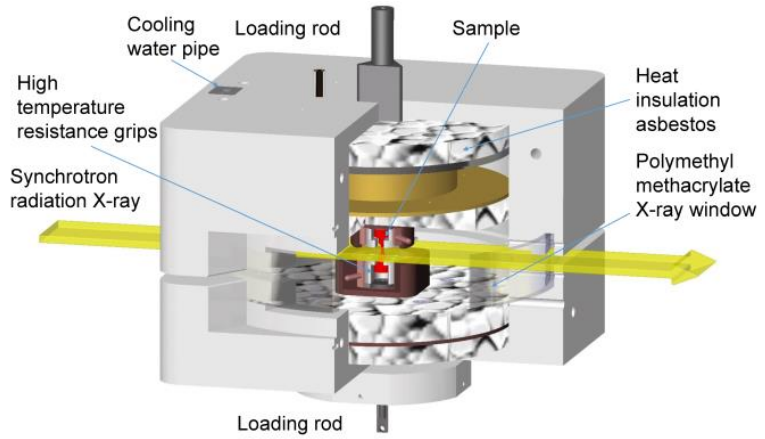

(b)

Fig. 2. (a) Schematic illustration of the in situ high temperature fatigue test rig for synchrotron radiation $\mathrm{X}$-ray computed microtomography; and (b) Cut away view of the heating chamber illustrating the X-ray transmission path through the heating chamber and sample.

The in situ rig (Fig. 2) was accommodated on the high-resolution SR- $\mu$ CT beamline (BL13W1) of the Shanghai Synchrotron Radiation Facility (SSRF) in Shanghai, China. Uniaxial isothermal high stress ratio tensile fatigue tests were performed in situ at a stress ratio of $0.5-0.7$ and a loading frequency of $\sim 6 \mathrm{~Hz}$. Three samples were fatigued at $250^{\circ} \mathrm{C}$ with the maximal loads of $95 \mathrm{MPa}$ (designated HT95), $105 \mathrm{MPa}$ (HT105) and 
$110 \mathrm{MPa}(\mathrm{HT} 110)$ and one at room temperature with 260MPa (RT260) as a reference.

The loads ensured that for all the tests the samples experienced significant plasticity each cycle, i.e. low cycle fatigue testing conditions. The specimen was heated from ambient temperature to $250{ }^{\circ} \mathrm{C}$ at a rate of $20{ }^{\circ} \mathrm{C} /$ minute, and then held at $250{ }^{\circ} \mathrm{C}$ for a half hour prior to mechanical loading. CT scans were undertaken after specific numbers of fatigue cycles, by interrupting the fatigue experiment and holding at the approximate maximum load. After each scan, the lower grip position was adjusted in order to ensure quasi constant stress amplitude all along cycling. Projections (radiographs) were acquired using a 2048×2048 pixel CMOS detector using a monochromatic $22 \mathrm{keV}$ photon energy beam. The parallel beam setup on BL13W1 gives a voxel size of $3.25 \mu \mathrm{m}$. The samples to detector distance was $\sim 180 \mathrm{~mm}$ giving rise to some in line phase contrast. Each scan comprised 720 radiographs acquired over $180^{\circ}$, each with an exposure time of $400 \mathrm{~ms}$. From a fatigue perspective, it should be noted that aluminium alloys can show elevated temperature creep under dwell loading conditions such as those used here periodically to allow the CT scans to be acquired. However we observed little elongational creep during the scan periods. Volumes were reconstructed using a Paganin algorithm and data post-processing was performed on the software PITRE3 ${ }^{\circledR}$ and PITRE3B ${ }^{\circledR}$ developed by SSRF and Italy Elettra, to output the 8 bit CT slice data, from which the commercial software $\mathrm{AVIZO}^{\circledR}$ was used to generate 3D internal geometries.

\section{Results}

\subsection{Defect population in as-manufactured samples}

The field of view comprised the full sample diameter $(1.4 \mathrm{~mm})$ over a length of 2.4 $\mathrm{mm}$, see Fig. 3a, and only those defects with dimensions greater than $11.2 \mu \mathrm{m}(>21$ voxels) in diameter were considered so as to suppress errors originating from image 
noise [32]. A relatively high number of small approximately equiaxed defects are evident. Both surface and internal defects can be seen, but the majority are internal defects having an irregular spatial distribution. It can be clearly seen from Fig. 3b that $80 \%$ of the defects have an equivalent diameter lying within $10-20 \mu \mathrm{m}$. The aspect ratio of the majority of defects lie between 1-1.5, see Fig. 3c indicating that a large number of essentially spherical small defects predominate in the as-received AlSi10Mg alloy. Contrary to the work by Larrosa et al. [13] in this case the defects appear to be randomly oriented rather than pancakes lying predominantly within the build plane and the distribution of sphericity is close to a Gaussian distribution centred approximate 0.9 , see Figs. $3 \mathrm{~d}$.

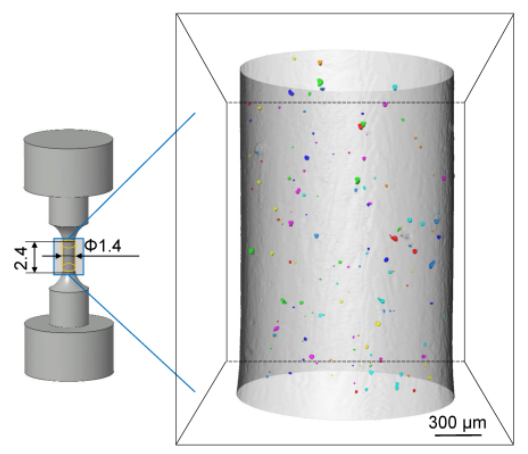

(a)

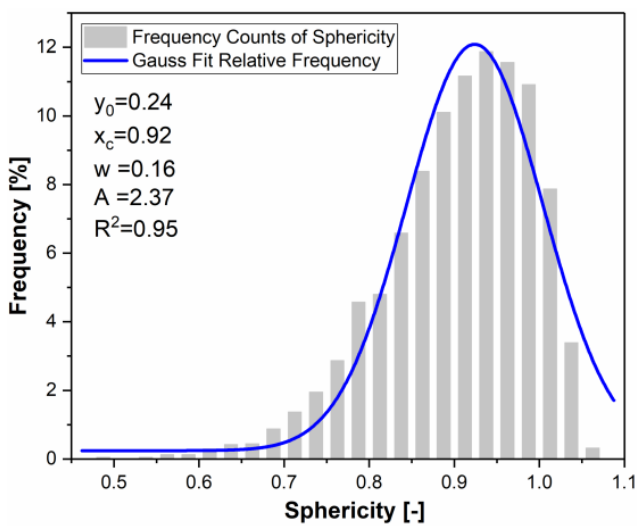

(c)

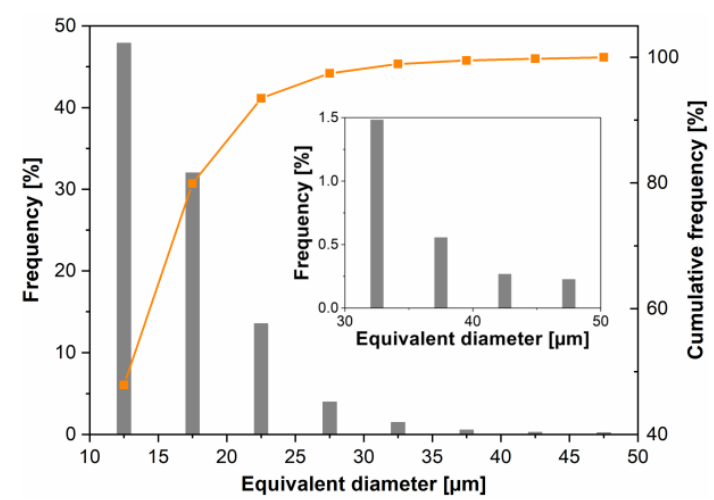

(b)

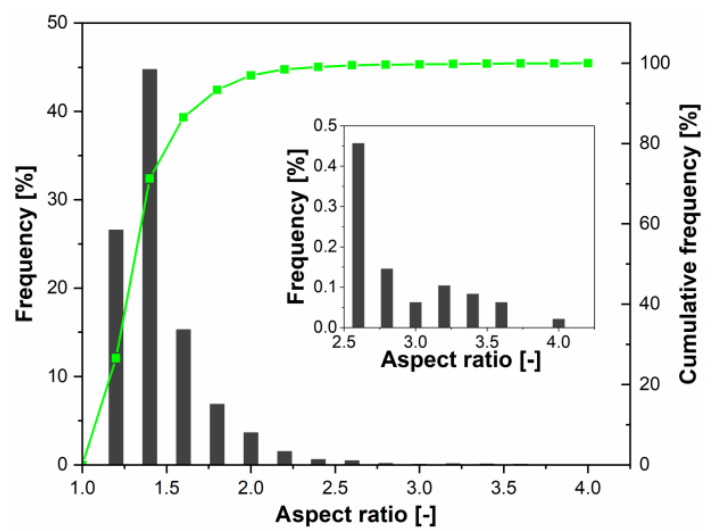

(d)

Fig. 3. (a) Schematic showing the field of view of the as-manufactured sample and a rendering of 3D micro-defects in sample HT95 prior to loading; (b) and (d) distributions of equivalent diameter and aspect ratio of defects and their cumulative frequency curves; and (d) the distribution of sphericity along with a Gaussian best fit curve $\left(y_{0}, x_{c}, A\right.$ : scale parameters; $W$ : shape parameter; $R^{2}$ : coefficient of determination). Here equivalent diameter denotes the diameter of an equivalent sphere having the same volume as the corresponding defect while sphericity [33] represents the ratio of the surface area of the 
equivalent sphere to that of the defect. The aspect ratio is the ratio of the semi-major axis and semi-minor axis of the ellipsoid representing the defect.

\subsection{Evolution of defect during tension-tension fatigue}

To study the defect evolution and damage accumulation in SLM AlSi10Mg alloy during cyclic loading the samples were monitored by time-lapse SR- $\mu \mathrm{CT}$. The high temperature fatigued samples eventually ruptured after 30,260 cycles (HT95), 5,755 cycles (HT105) and 180 cycles (HT110) respectfully while the fatigue life for the room temperature test specimen (RT260) was 38,445 cycles. The evolution of defects in HT105 and RT260, as a function of the numbers of fatigue cycles and the local longitudinal strain (denoted hereafter $\varepsilon_{l}=\ln \left(A_{0} / A_{c}\right)$, where $A_{0}$ is the initial crosssectional area and $A_{c}$ the current cross-sectional area), are shown in the reconstructed 3D SR- $\mu$ CT images and 2D slices in Figs. 4. The behaviours look very much like the classical void nucleation and growth under tensile plastic straining observed by Guo et al [34]. With increasing number of fatigue cycles, the top of the gauge length extends and macroscopic necking occurs. Evidently, the defect size and density in the necked volume increases with the number of cycles (from i) to iv)) for both samples. Some defect coalescence is also evident in both samples and this will be analysed in later sections. Comparing HT105 to RT260 in Figs. 4 it is clear that the reduction in area (necking strain) is greater for the elevated temperature test $\left(\varepsilon_{l} \sim 0.94 \mathrm{cf} 0.7\right)$ and this is also reflected in larger aspect ratio defects and a higher final porosity $(\sim 0.74 \%)$ than at room temperature $(\sim 0.51 \%)$ in the necked region despite having similar initial porosity $(\sim 0.30 \%)$. The trends in all four samples were broadly similar suggesting that the damage accumulation is representative of the behaviour of defects during LCF cycling at RT and elevated temperature despite the stochastic nature of the fatigue lives which depends on the scatter in the size of the largest as-manufactured defect sizes. 

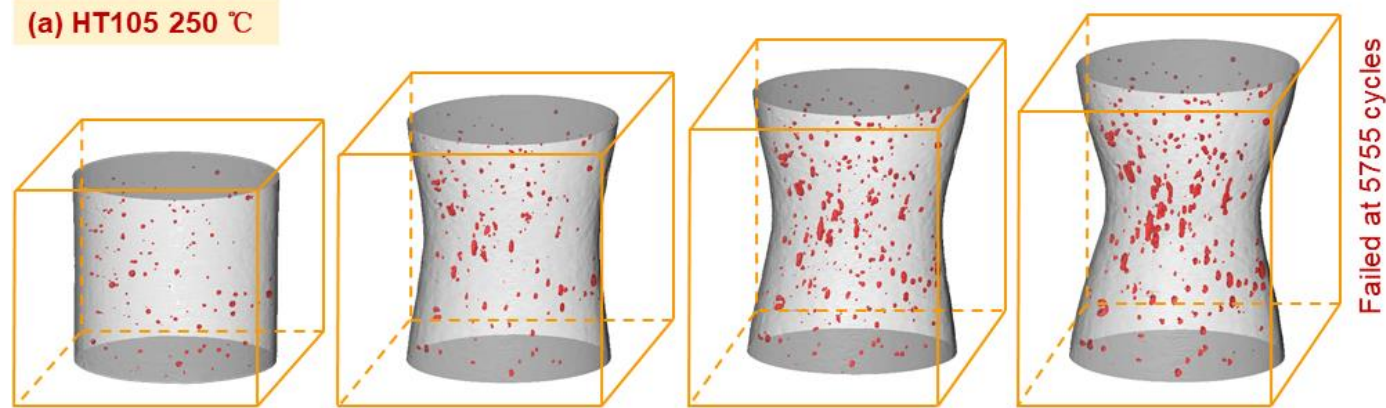

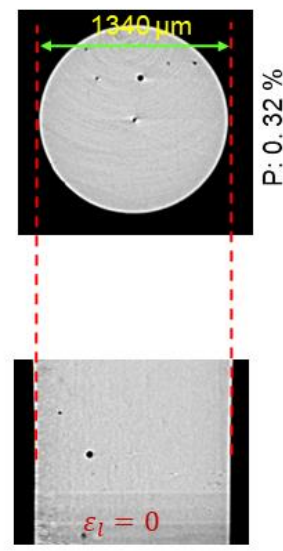

i) 0 cycles

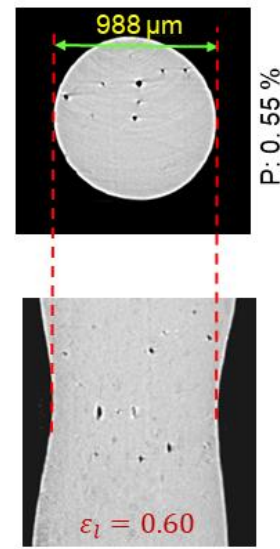

ii) 4500 cycles
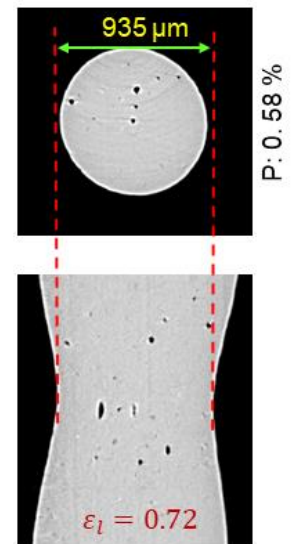

iii) 5055 cycles
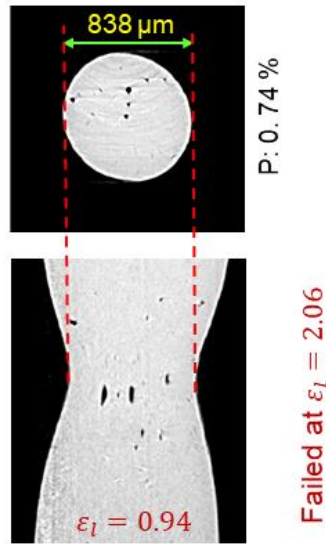

iv) 5655 cycles

(b) RT260 Room temperature
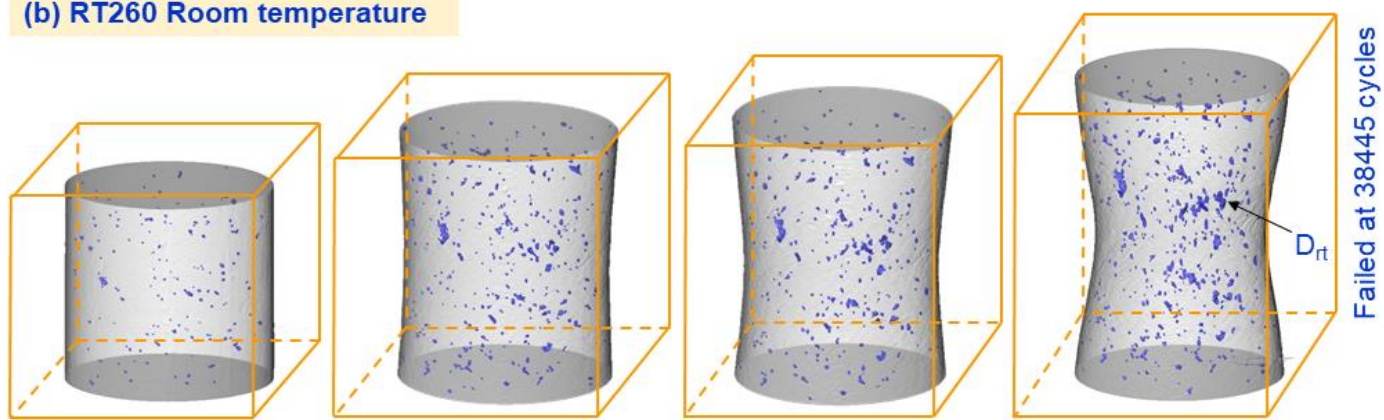

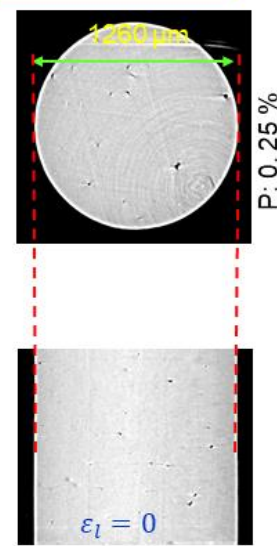

i) 0 cycles

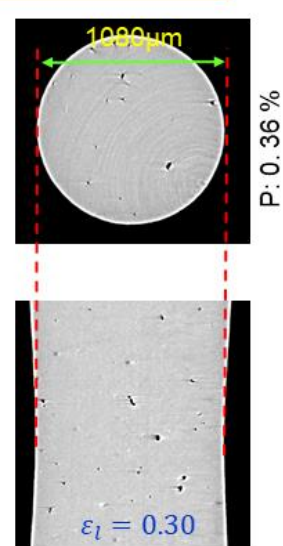

ii) 20000 cycles
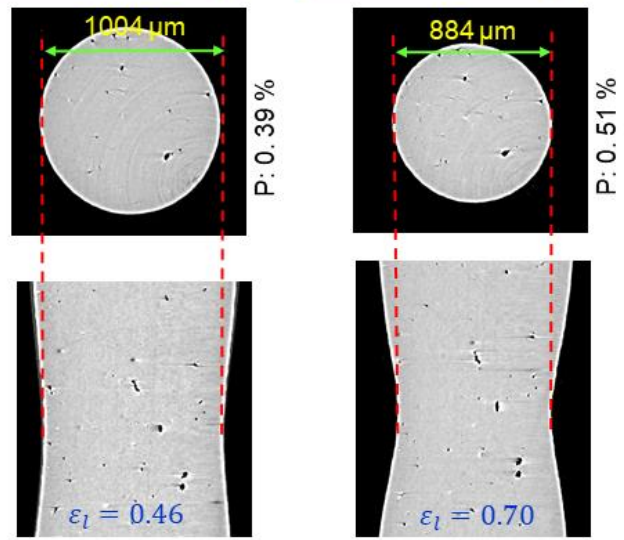

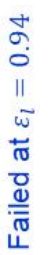

iv) 37007 cycles

Fig. 4. Time -lapse images of a) the sample (HT105) tested at $250^{\circ} \mathrm{C}$ and peak load of $105 \mathrm{MPa}$ and b) the sample (RT260) tested at room temperature test and peak load of $260 \mathrm{MPa}$ as a function of numbers of cycles showing the 3D rendering of the voids (top), a virtual mid-plane slice (middle), and a diametral slice (bottom) in each case. 
The distribution of defects in the fractured regions of high temperature fatigues samples are displayed in the magnified volume 3D renderings as shown in Figs. $5 \mathrm{a}, \mathrm{b}$ and c. The aspect ratio of the defects in all samples falls off sharply with distance from the fracture surface. The extent and orientation of the elongation of the defects reflect the underlying plastic flow lines such that their angle of inclination to the tensile axis increases with radial distance from the central axis. Fig. 6a shows the variation of defect volume fraction and local longitudinal strain with respect to the distance from central slice (i.e. the distance from the fracture plane see Fig. 5). It is evident that the final fracture occurs at the region of highest longitudinal strain which, unsurprisingly, is also where the defect volume fraction is highest. Further than $\sim 300 \mu \mathrm{m}$ from the fracture surface the increase in porosity becomes negligible despite experiencing an accumulated longitudinal strain of $\sim 1$ (Figs. $6 \mathrm{a}$ and b).

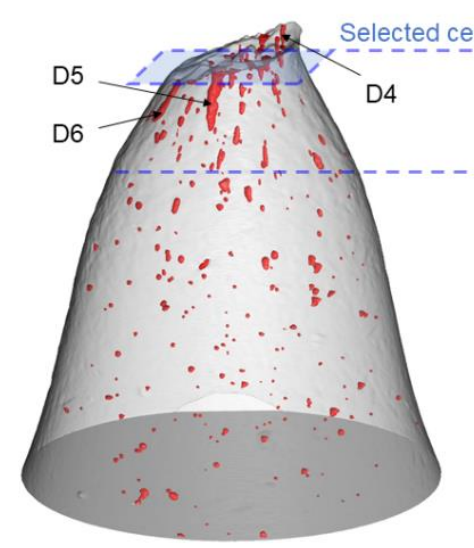

(a) HT95

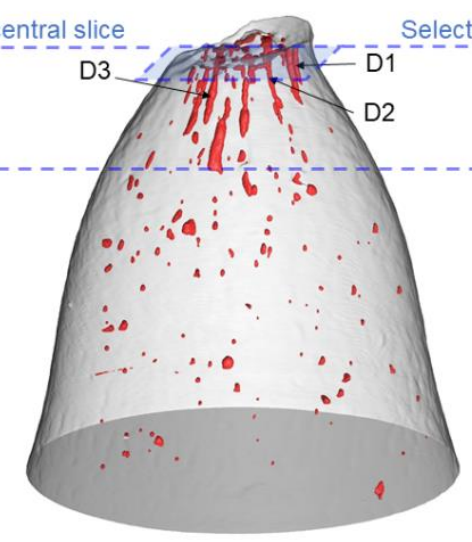

(b) $\mathrm{HT} 105$

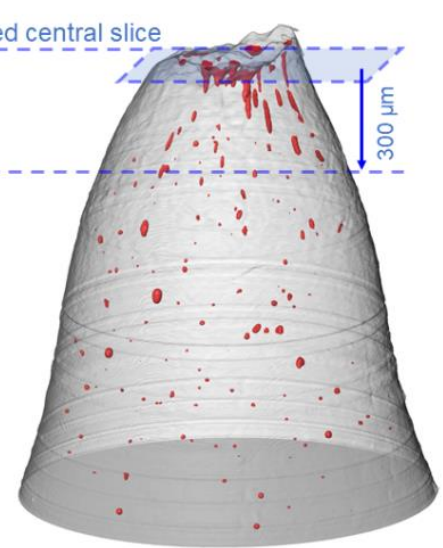

(c) HT110

Fig. 5. 3D rendering of the fractured heads of HT95 (a), HT105 (b) and HT110 (c): six exceptionally large defects are defined as D1-D6 and slices having the smallest integral cross-section of each head are defined as central slices. 


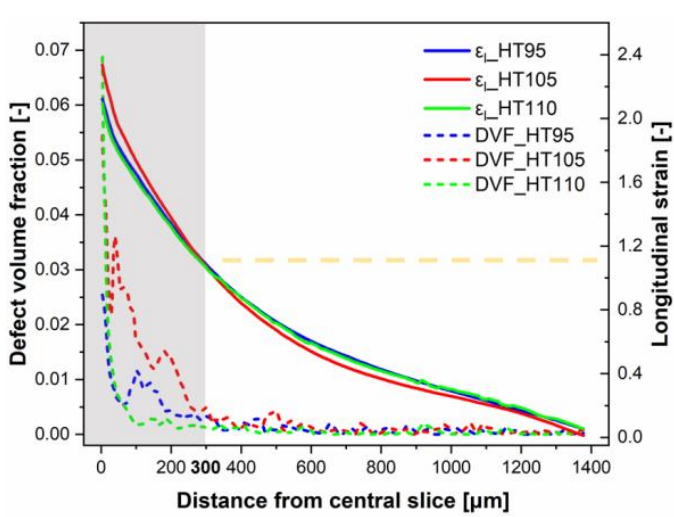

(a)

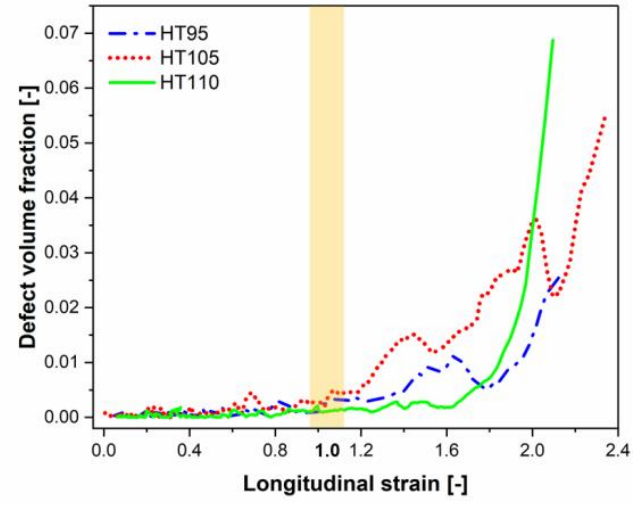

(b)

Fig. 6. (a) Defect volume fraction and longitudinal strain variation as the function of distance from the central slice (smallest cross sectional area, see Fig. 5) and (b) defect volume fraction curve with respect to the longitudinal strain.

\section{Discussion}

\subsection{Defect growth: elongation and rotation}

The manner of defect growth in the necking region for high temperature low cycle fatigue is exemplified by the study of three defects within HT95 as a function of fatigue cycle shown in Fig. 7. It is clear that the axial extension is much greater than the circumferential expansion of the defects. The elongation rate in the loading direction is $\sim 10$ times larger than the propagating rate in the circumference direction. Some defects, such as D3, also tilt under the influence of shear in the necked region. This is likely due to the position of the defects relative to the surface of the specimen where there is significant component of shear strain under plane stress conditions. The variation in defect aspect ratio with cycling is plotted in Fig. 8a which tends to increase more rapidly towards the end of the test, while Figs. $8 \mathrm{~b}$ indicates that this is primarily related to the increase in the strain rate. The similar slopes of all lines shown in Fig. 8c show that the aspect ratio is almost linearly correlated to the corresponding local accumulated strain for each defect and the increasing rate is similar for all the asmanufactured defects although they differ in size, morphology and location. This experimental result is in line with the defect radius increasing at a rate in line with the 
incremental strain accumulated each cycle in line with the model presented by Kanvinde et al. [31], which will be discussed later.

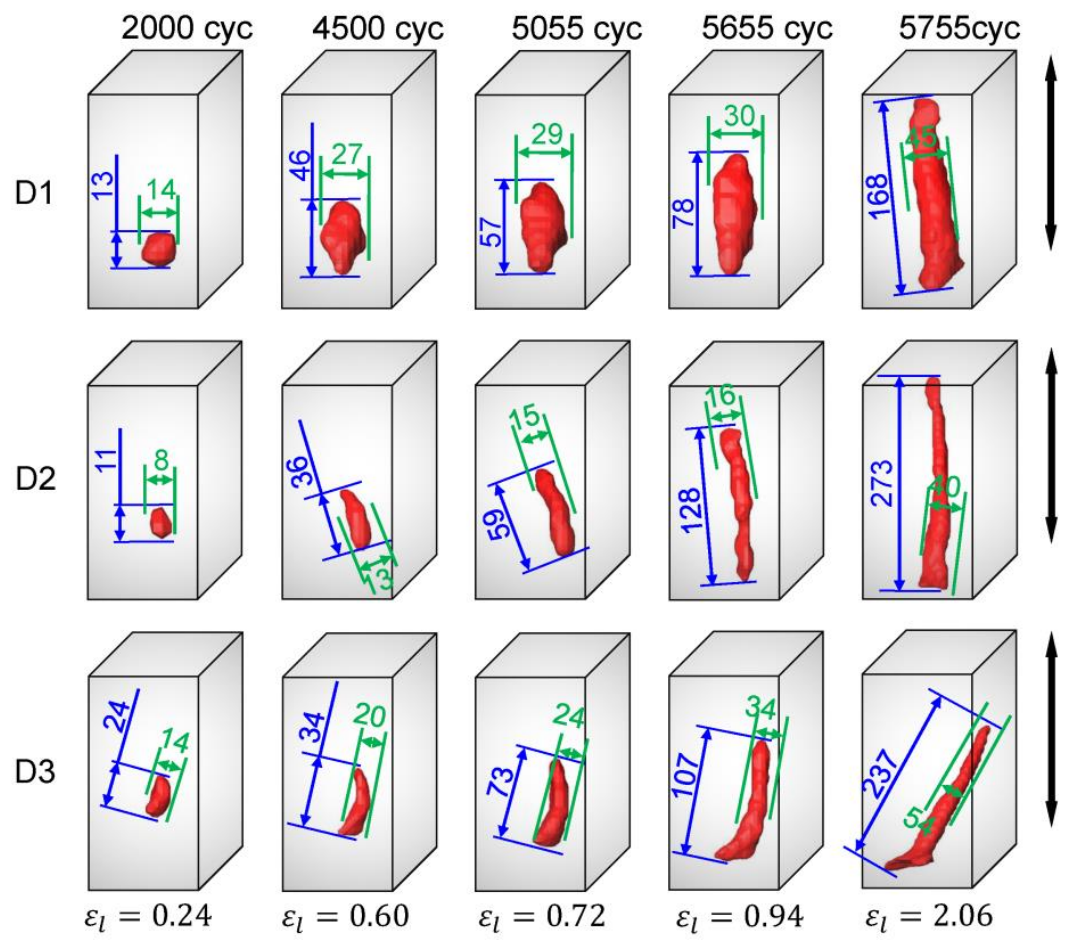

Fig.7. The evolution of three defects (D1, D2 and D3) within the HT105 sample (see Fig. 6b) as a function of the number of cycles and longitudinal strain. All dimensions are in $\mu \mathrm{m}$. 


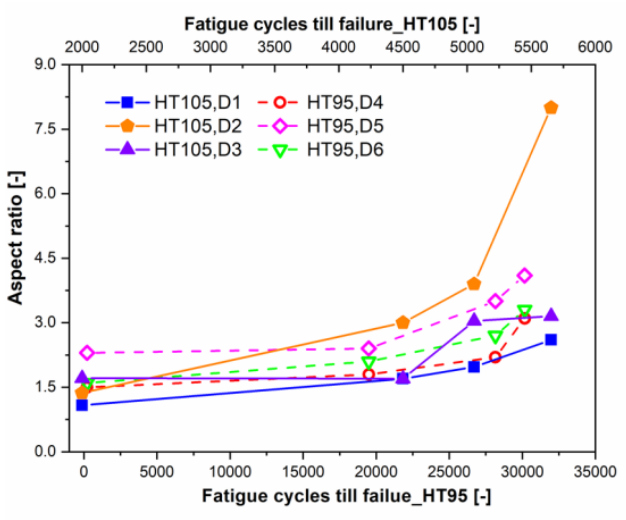

(a)

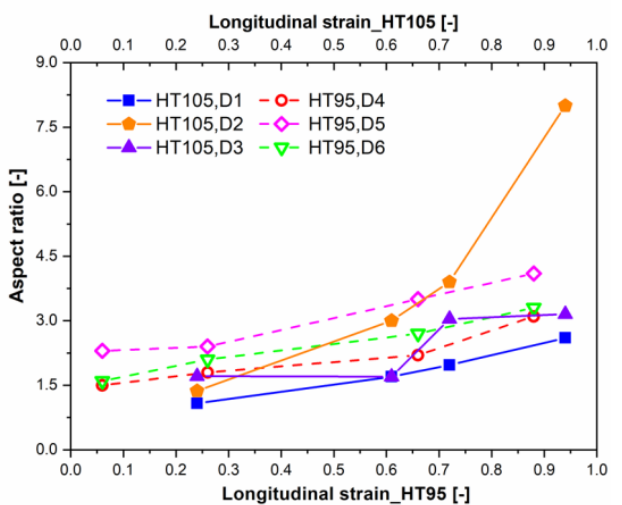

(b)

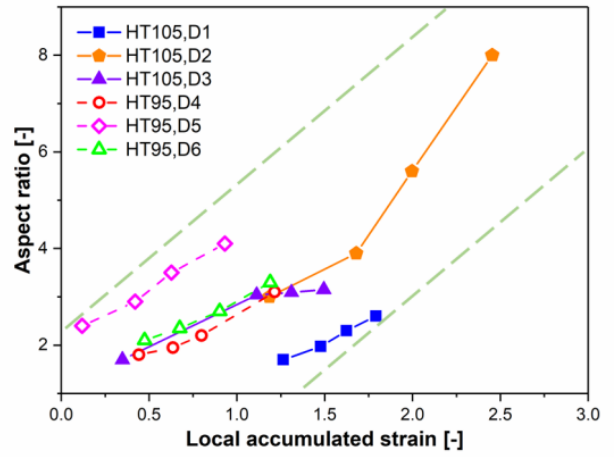

(c)

Fig. 8. Plots showing the evolution of the aspect ratio of three defects in HT105 (D1-D3) and three in HT95 (D4- D6): with respect to (a) the number of cycles, (b) the overall longitudinal strain and (c) the local accumulated strain. The locations of D1-D6 are illustrated in Fig. 5.

The SEM images shown in Fig. 9 also provide the complementary microstructure information of the final status of elongated defects. Consistent with the $\mu \mathrm{CT}$ observations, the elongated defects are mostly distributed within the highly necked region. It is also clear from the magnified sub-figure that the further from the rotational axis of sample the more tilted. The morphology shown in Fig. 9b suggests that for a single defect arising from SLM, the region (see the yellow dashed zone) on the opposite side of the fractured surface might act as an internal constraint during the elongation event, and so as the defects extends essentially toward the highly necked zone under local plastic deformation, leaving evidence of the local strain flow on the other side. 

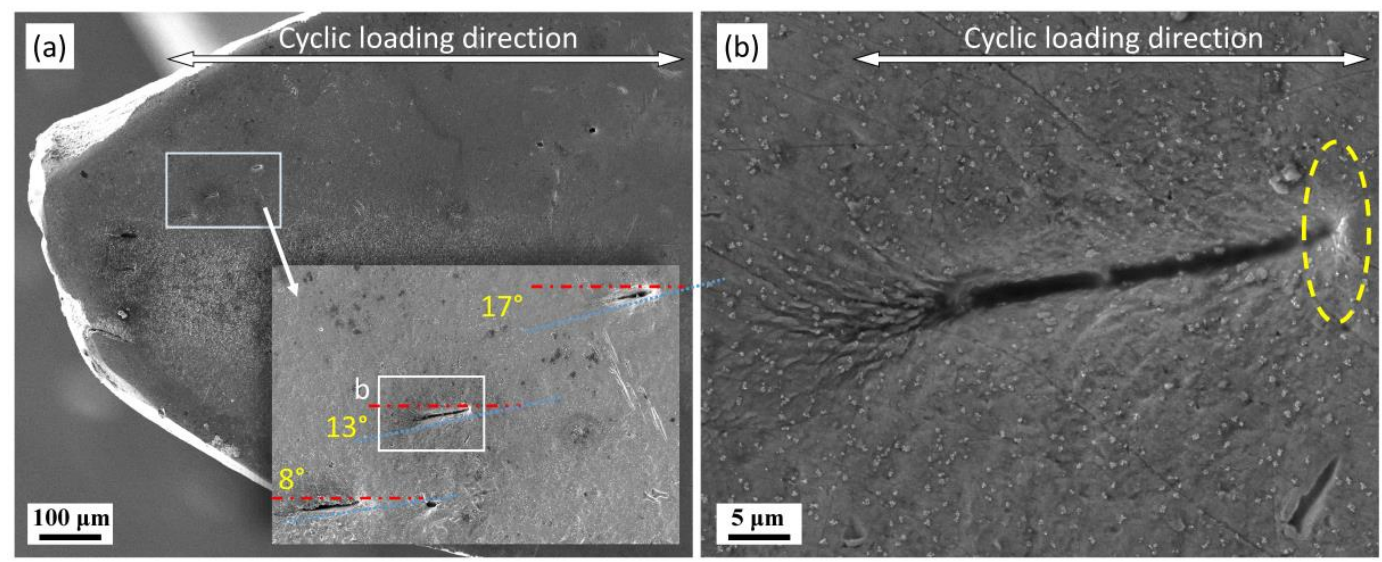

Fig. 9. SEM micrographs at different magnifications of the longitudinal cross section of fractured HT105 showing (a) elongated defects distribution on the cutting surface and (b) magnified region of interest containing a typical elongated defect.

The phenomena of cyclic void growth coupled with damage accumulation under large inelastic strains has been studied by Kanvinde et al. [31], but for ultra low cycle fatigue in steels. Accordingly, each cycle can be regarded as a combination of rising excursions and falling excursions and the defect radius during cyclic loading can be expressed by the following equation, which is an extension of the classical Rice and Tracey model [35]:

$$
\begin{aligned}
& \ln \left(R / R_{0}\right)_{\text {cyclic }}=\sum_{\text {Rising excursions }} C_{1} \int_{\varepsilon_{1}}^{\varepsilon_{2}} \exp (|1.5 T|) d \varepsilon_{p}-\sum_{\text {Falling excursions }} C_{2} \int_{\varepsilon_{1}}^{\varepsilon_{2}} \exp (|1.5 T|) d \varepsilon_{p}, \\
& \ln \left(R / R_{0}\right)_{\text {cyclic }}=C\left(\sum_{\text {Rising excursions }} \int_{\varepsilon_{1}}^{\varepsilon_{2}} \exp (|1.5 T|) d \varepsilon_{p}+\sum_{\text {Falling excursions }} \int_{\varepsilon_{1}}^{\varepsilon_{2}} \exp (|1.5 T|) d \varepsilon_{p}\right),
\end{aligned}
$$

where $R$ represents the current equivalent defect radius; $R_{0}$ the initial equivalent defect radius; $T$ the stress triaxiality; $C_{1}$ and $C_{2}$ two constants used to allow for different rates of defect growth with respect to the plastic strain; $\varepsilon_{p}$ the incremental equivalent plastic strain as well as $\varepsilon_{1}$ and $\varepsilon_{2}$ the plastic strains at the beginning and end of each excursion respectively. As the applied stress ratio was $>0$ and lacking more extensive data, we assume that $C=C_{1}=-C_{2}$, the defect elongation during tensile-tensile cycling can be 
expressed by Eq. (2). This is similar to the one for monotonic loading in that both relate defect growth to positive triaxiality and plastic strain histories. The maximal stresses applied in this paper were such high that all were close to the corresponding UTS at the appropriate test temperature. The high stress ratio (0.5 - 0.7) also means that the plastic strain range is relatively small, which may weaken the capability of cyclic load reversals in competing with monotonic modes of ductile damage. Furthermore, the low level of constraint associated with the specimen design facilitates extensive plastic deformation and hence pronounced necking and void growth per cycle. However, as the necking becomes more pronounced the stress triaxiality increases locally and a consequent reduction in ductility, stimulating void coalescence and secondary (appox. spherical) microvoid nucleation and growth just before failure, as discussed below.

\subsection{Defect coalescence and fracture}

With increasing fatigue cycle the SLM pores grow and then start to coalesce which can be clearly seen in Fig. 10a for both room and elevated temperature LCF. It seems that coalescence favours defects positioned with respect to one another such that shear at $45^{\circ}$ can bring about coalescence. This suggests that shear deformation may have a strong effect on the defect coalescence process. This has been studied by other researchers [36,37] and even monitored experimentally [38,39] monotonic tension. Weck at al. [38] found that in Glidcop samples, an instability oriented at $45^{\circ}$ occurs between the voids due to the coalescence occurs at lower strains and Li et al. [39] found that void coalescence was primarily along $55^{\circ}$, in pure copper $(99.9 \%)$, which orients similarly to the shear deformation around the severe necking zone. For ductile fracture, the Brown and Embury model [40] predicted that if the shear bands at $45^{\circ}$ can be 
reached, the voids coalescence often occurs. This is also described in the extended version of the Thomason model $[37,41]$ as:

$$
\frac{\sigma_{\text {overall }}}{\sigma_{\text {yield }}}=\frac{1-S_{\text {eff }}^{2}}{\sqrt{S_{\text {eff }}}}\left[\frac{\alpha_{T h}\left(1-S_{\text {eff }}\right)^{2}}{A_{\text {eff }}^{2} S_{\text {eff }}^{\frac{3}{2}}}+1.24\right]
$$

where $\sigma_{\text {overall }}$ stands for the overall stress component normal to the localization plane, $\sigma_{y i e l d}$ the yield stress, $A_{\text {eff }}$ the effective void aspect ratio, $S_{\text {eff }}$ the effective void spacing, and $\alpha_{T h}$ depends on the strain hardening exponent [36]. In accordance with the definitions in [42] the values of the effective spacing $S_{\text {eff }}$ and effective aspect ratio $A_{e f f}$ are obtained as 0.48 and 1.1 respectively for D5 and $\alpha_{T h}$ is simplified as 0.1 , see Fig. 10b and Table 3 for measured parameters determined along the centre to centre direction.

Table 3

The effective parameters determined along the centre to centre direction, see Fig. 10b. All in $\mu \mathrm{m}$.

\begin{tabular}{ccccccccc}
\hline$S_{\text {center }}$ & $R_{C 1}$ & $R_{C 2}$ & $R_{N 1}$ & $R_{N 2}$ & $a_{1}$ & $b_{1}$ & $a_{2}$ & $b_{2}$ \\
\hline 54 & 10 & 19 & 9 & 24 & 5 & 10 & 20 & 19 \\
\hline
\end{tabular}

Given the yield stress $\sigma_{\text {yield }}=101 \mathrm{MPa}$ for SLM AlSi10Mg at $250{ }^{\circ} \mathrm{C}$, the defect coalescence condition for D5 is $125 \mathrm{MPa}$ which is close to the corresponding overall stress $111 \mathrm{MPa}$ gained from experiment results. This quantitatively explains the coalescence event, on D5 and its neighbour, being activated at $\sim 24,000$ cycles and aligns with the established theories underpinning the Thomason model for monotonic tensile loading. 

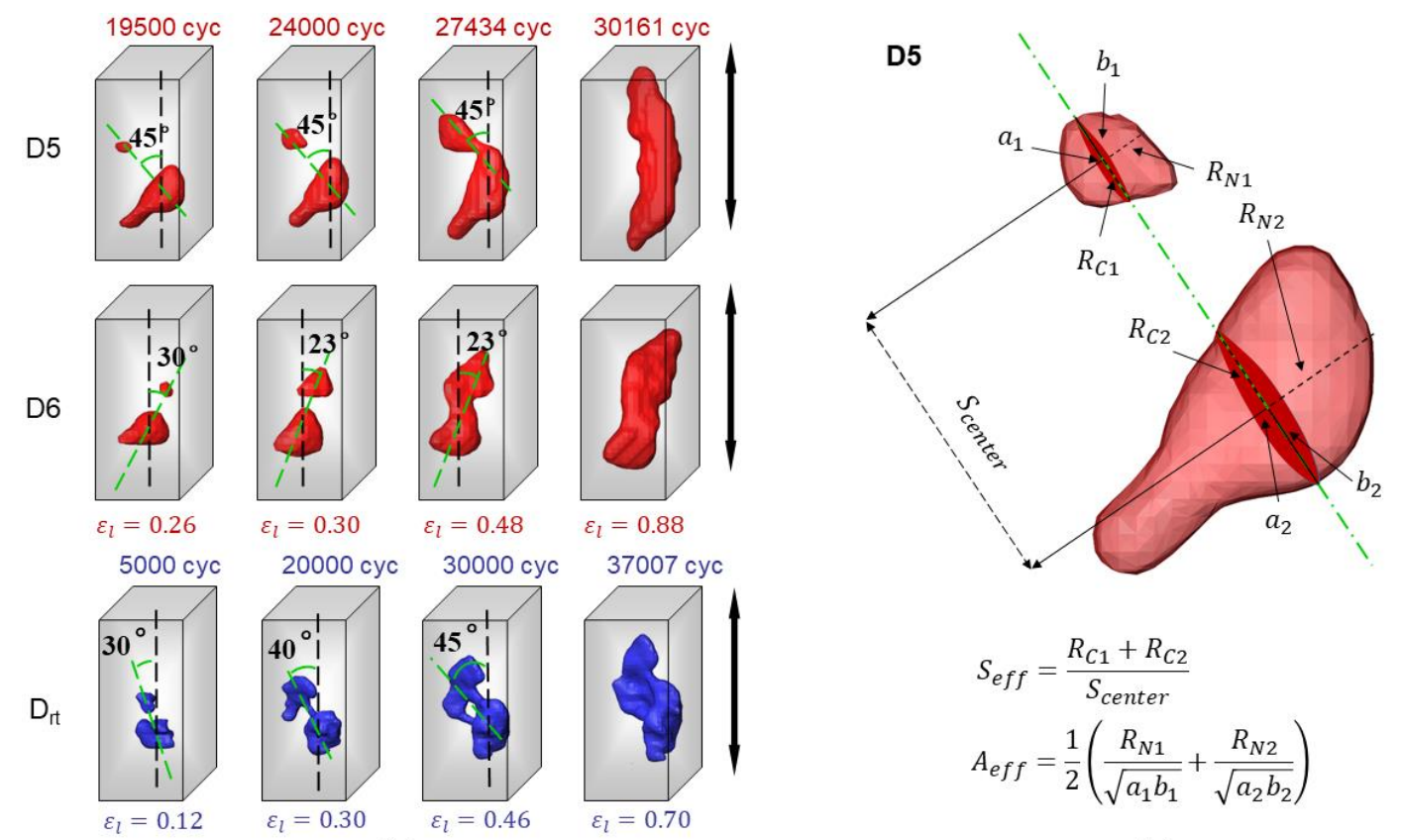

(a)

$$
\begin{aligned}
S_{\text {eff }} & =\frac{R_{C 1}+R_{C 2}}{S_{\text {center }}} \\
A_{\text {eff }} & =\frac{1}{2}\left(\frac{R_{N 1}}{\sqrt{a_{1} b_{1}}}+\frac{R_{N 2}}{\sqrt{a_{2} b_{2}}}\right)
\end{aligned}
$$

(b)

Fig. 10. (a) 3D rendering of classical defect coalescence process. Defects D4, D5 and D6 are extracted from sample HT95 and $D_{\text {rt }}$ is selected from RT260, see Fig. 4b and Fig. 5a. (b) Definition of the effective parameters used to apply the extended Thomason model for coalescence criterion.

Fig. 11a shows some evidence for the early stage of coalescence between two elongated defects. However, it can also be seen that this is not the case for the majority of the fracture surface which suggests that failure is largely precipitated by the nucleation of a secondary population of microvoids which occur in the hydrostatic stress zone of the neck. The very small size $(\sim 1 \mu \mathrm{m}$ in diameter $)$ of the equiaxed dimples, which dominates the morphology of central propagation zone, reveals that important role of the formation of secondary microvoids in this fatigue failure process just as for monotonic straining. A magnified SEM image (Fig. 11b) of the equiaxed dimples shows eutectic Si particles are evident at the bottom of these small dimples and microcracks encountering eutectic particles also exist on the fracture surface. It is possible that the accumulation of dislocations around these particles has resulted in stress concentrations sufficient to crack of the eutectic Si particles or to decohere them from Al-matrix happens [19]. Subsequently, the nucleation of a secondary population of microvoids between those elongated defects which are mostly located on the smallest 
cross sectional plane, greatly accelerates the void coalescence and internal defect induced fatigue crack propagation locally. This has been observed by Lassance et al. [43], but only under monotonic loading.

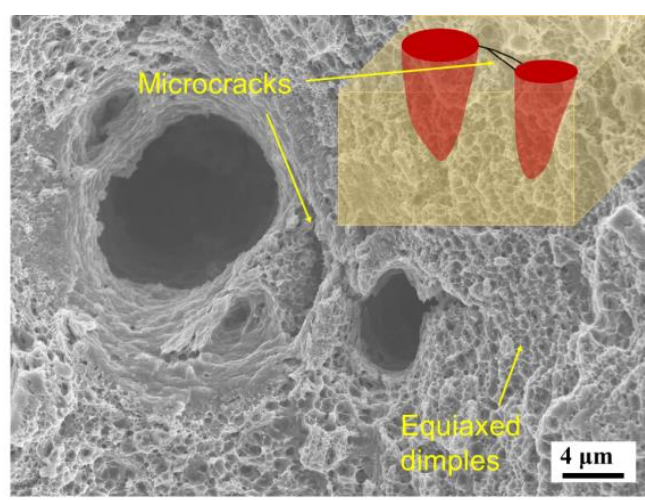

(a)

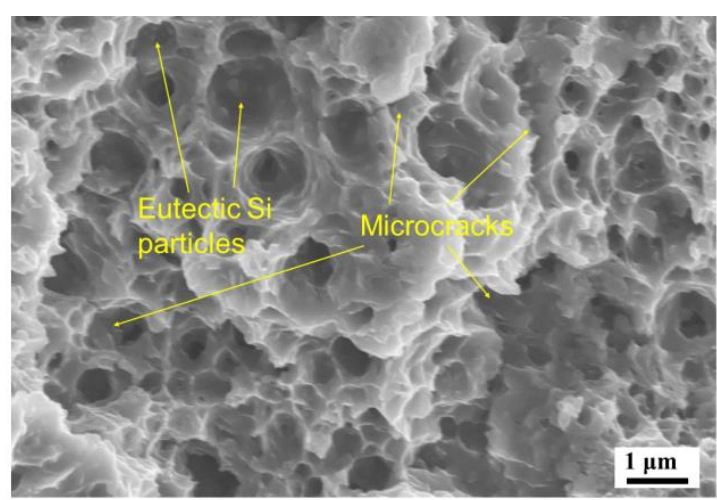

(b)

Fig. 11. SEM images of the HT95 fracture surface showing (a) elongated defects starting to coalescence and (b) eutectic Si particles observable at the bottom of the dimples on the fracture surface of HT105.

Fatigue fracture under extreme cyclic plasticity preferentially occurs by complex fracture-fatigue interaction mechanisms that are closely analogous to monotonic ductile fracture initiation [44]. The low magnification SEM images of the fracture surface shown in Fig. 12 show a dimple morphology indicating void nucleation, growth, and coalescence. All the fractured surfaces consist of two main regions (separated by red dashed lines); i) a microvoid coalescence zone also containing a few large voids in the centre and ii) a fast fractured shear lip zone surrounding it. It is also observable that rather than a single initiation site a number of large dimples (corresponding to elongated defects monitored in $\mu \mathrm{CT}$ ) surrounded by equiaxed microdimples (corresponding to secondary voids) are visible in the central crack propagation zone. A shear dimple zone is evident at the edge of some large dimples, which indicates a potential cross sectional crack initiation cite. Normally, the primary voids nucleated from large inclusions usually are assumed to be present (nucleated) at the beginning of plastic loading, while in this work the pre-existing SLM defects act as the primary voids and grow from the beginning of cyclic loading. A rapid development of damage among 
eutectic Si particles then links these elongated defects leaving cracked eutectic $\mathrm{Si}$ particles in microdimples. Around the periphery, the shear lip shaped smooth surfaces are full of shear dimples, which indicates the shearing driven final fast fracture.
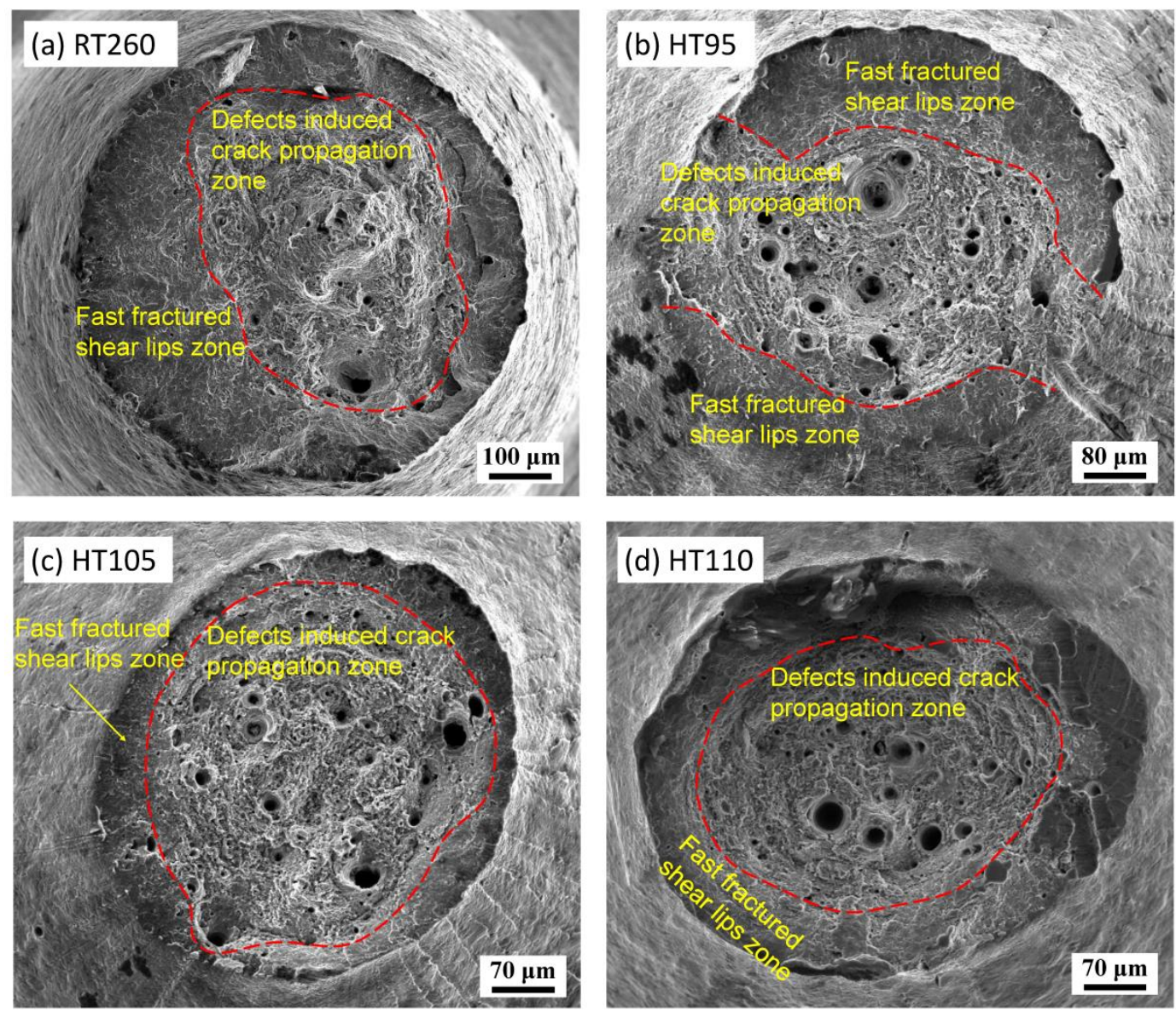

Fig. 12. Typical low-magnification SEM images of samples: (a) room temperature with fatigue life of 38,445 cycles, (b) $250{ }^{\circ} \mathrm{C}$ with 30,260 cycles, (c) $250{ }^{\circ} \mathrm{C}$ with 5,755 cycles and (d) $250{ }^{\circ} \mathrm{C}$ with 180 cycles, showing the overall view of the fracture surfaces.

Fig. 13 shows the population of large, elongated defects as a function of cycling and strain. It is clear from Fig. 13a that as the fatigue test continues, the significant growth of the elongated defect population happens in specimens fatigued at $250{ }^{\circ} \mathrm{C}$ while the rate at which this population increases is quite slow under room temperature. Consequently, there are only 13 elongated defects are detected in RT260 at the stage just prior to fracture. This difference in the development of this elongated defect population during cyclic loading eventually leads to a higher number of deep dimples (corresponding to elongated defects) exposed on fracture surfaces of the high temperature samples 
compared to RT260. It also can be seen from Fig. 13a that the shorter the life the more rapidly the elongated defects develop. However when the defects are plotted against the longitudinal strain in Fig. 13b the data broadly come together suggesting that level of accumulated strain controls the development of such defects, which supports the result indicated by Fig. 8c further. This suggests that the temperature primarily influence the plastic deformation during low cycle fatigue which then controls that defects elongation behaviour.

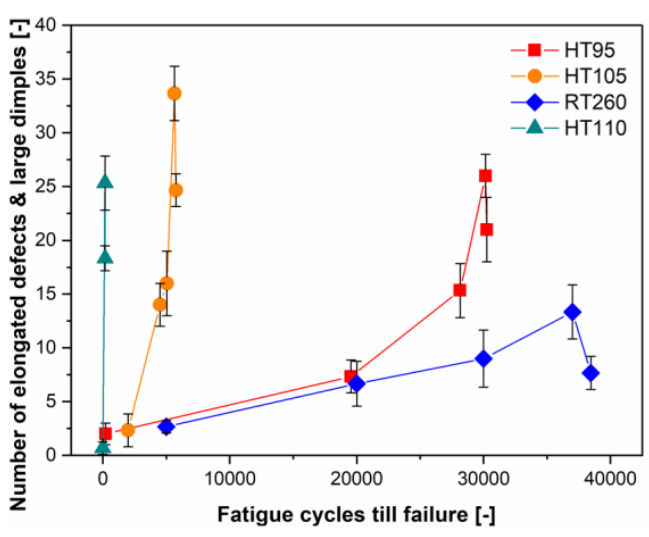

(a)

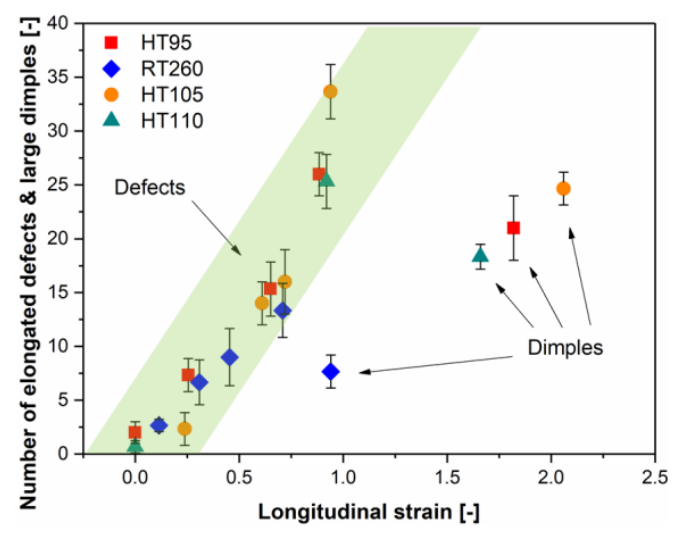

(b)

Fig. 13. Plots showing the number of elongated defects (filled symbols) and voids on fracture surface (cross symbols) (a) as a function of the number of cycles to failure and (b) as a function of local longitudinal strain. (Only defects with an aspect ratio $>2$ and a volume $>10000 \mu \mathrm{m}^{3}$ are considered in the CT analysis and only those dimples with a ferret diameter larger than $12 \mu \mathrm{m}$ in the SEM, see Fig. 12, are considered).

\subsection{Tension-tension fatigue damage mechanism of SLM AlSi10Mg alloy at $250^{\circ} \mathrm{C}$ and}

\section{high stress conditions}

Fig. 14 illustrates schematically the tensile low cycle fatigue damage mechanism of SLM AlSi10Mg alloy under $250{ }^{\circ} \mathrm{C}$ and high stress conditions. The large defects arising from SLM elongate under local plastic straining and then coalescence through microvoiding as the hydrostatic constraint becomes significant due to the necking. This microvoiding arises from microcracks or decohesion of eutectic Si particles. The defects enlargement that occurs at sufficiently high triaxiality, the region close to the edge of the sample, is usually accompanied with rotations in addition to the longitudinal 
extension. Generally, these steps, (a)-(c) of Fig. 13, take up majority time of the fatigue life till the macroaxial strain reaches approximate 0.7 , such as 93\% for HT95 and 89\% for HT105 in this work. The phenomenon of large defect elongation, rotation and coalescence are much less extensive with the distance from the central section of necking bulk due to the lower local plastic strain. At some point the hydrostatic constraint becomes sufficient for the microvoids to start to form in the middle of the gauge and start to link the large elongated defects together. As the macroscopic necking appears simultaneously, the SLM defects induced internal crack initiates in the cross section due to the high triaxiality, which is the main reason of the central zone with large population of equiaxed dimples accompanied with some shear dimples around the opened edged of large defects. The nucleation of a secondary population of microvoids between those elongated defects which are mostly located on the smallest cross sectional plane, greatly accelerates the coalescence and internal cross section crack propagation and generates large dimples and equiaxed microdimples, with cracked hard particles at the bottom, on both separated surfaces. At the final stage of cyclic plasticity when the longitudinal strain exceeds $\sim 0.9$, with the increasing area of central crack propagation zone, the rest outermost circumferential region ruptures due to shear stress and so as result in the cup and cone shaped ductile fracture surfaces. 


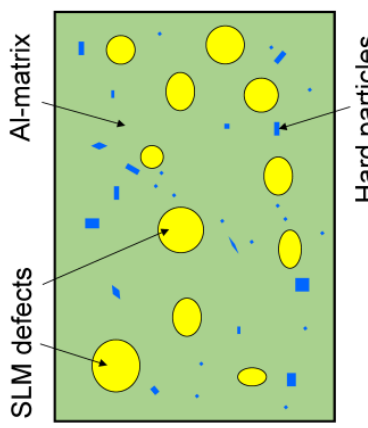

(a)

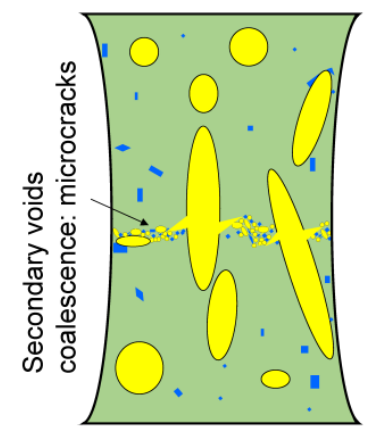

(d)

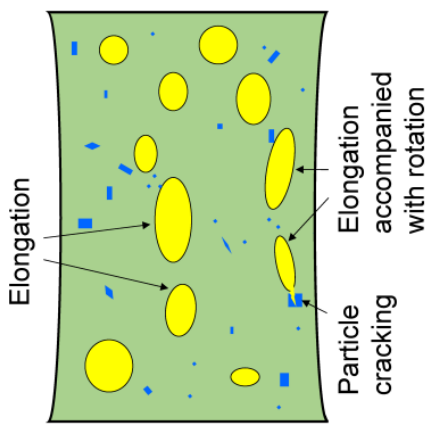

(b)

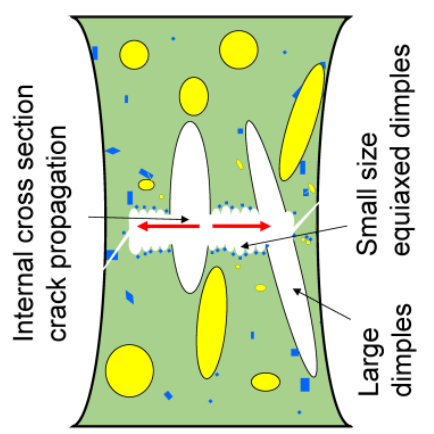

(e)

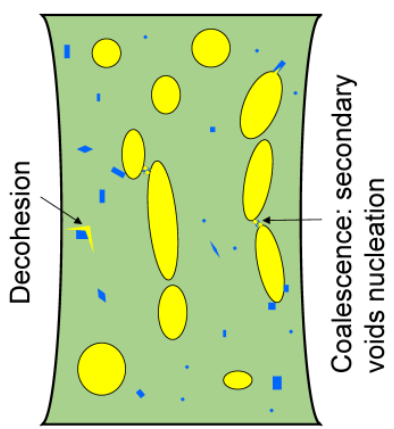

(c)

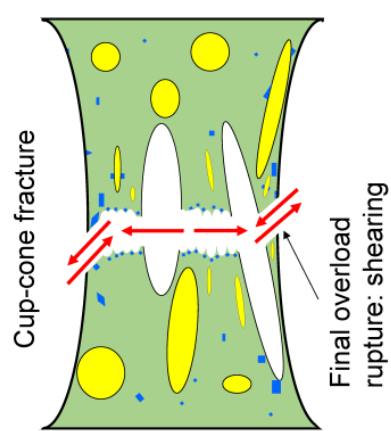

(f)

Fig. 14. Schematic representations of high stress fatigue damage mechanism of SLM AlSi10Mg alloy under $250^{\circ} \mathrm{C}$. (a) Initial status of the sample with the large SLM defects simplified as spheres and ellipses. (b) Elongation of large defects occurs near the central necking region which is largely due to the longitudinal strain (see Fig. 13b). (c) The adjacent defects coalescence happens when the distance between two defects is close to their own size. (d) Internal crack initiates in the cross section due to the triaxiality stress. (e) The secondary microvoids nucleation greatly accelerates the internal cross section crack propagation. (f) Finally, the cup and cone ductile fracture happens.

\section{Conclusions}

Time lapse CT has clarified the role of the defects on high temperature fatigue damage accumulation of AlSi10Mg alloy under high stress ratio low cycle fatigue (generalised plasticity) conditions. Results obtained have provided quantitative data on the evolution of SLM defects elongation, rotation and coalescence and the role of the underlying microstructure on ductile fracture of this alloy.

The key findings are summarised as:

(1) The SLM defects elongate slowly at first and then increasingly quickly during tension-tension fatigue in accordance with the local longitudinal strain. Little elongation is seen below a strain of $\sim 1$ local axial strain. The original defects 
elongate along the loading direction, at the rate of $\sim 10$ times larger than the lateral direction growth rate and eventually become extremely long defects.

(2) Defect elongation is driven by the plastic strain increment each cycle and the growth rate of elongated defects number seems to be linearly correlated to the accumulated longitudinal strain at room and elevated temperature. The temperature primarily influences the plastic deformation (the necking of samples at $250{ }^{\circ} \mathrm{C}$ were more significant than that of room temperature) during fatigue which then controls that defect elongation behaviour.

(3) Towards the later stages of fatigue life, elongated defects tilt under the influence of shear in addition to the extensional deformation is also observed on those defects close to the surface of samples in the necking region.

(4) Defects coalescence is more likely to be determined by the nucleation of secondary microvoids nucleation than the coalescence of the larger voids although some large void coalescence is observed largely for voids located at $45^{\circ}$ to one another suggesting shear stress may play an important role on large defects coalescence in high temperature cyclic plasticity.

(5) The microvoids only nucleate just before failure (when the longitudinal strain exceeds $\sim 0.9$ ) in the precise location of failure and originate from the cracking of the eutectic Si particles or decohesion from Al-matrix.

(6) In the final stage of cyclic plasticity, the outermost circumferential region ruptures due to shear giving rise to cup and cone shaped fracture surfaces characteristic of ductile tensile failure.

(7) It is noteworthy that in contrast to HCF where near surface defects often cause fatigue cracking, under high stress ratio LCF the defects in the centre (triaxial 
stress region) grow and cause failure. This behaviour is in line with previous studied of ULCF failure.

It should be recognised that these tests were undertaken on small (low triaxial constraint) test pieces. One would expect to see less tensile plasticity (e.g. necking and void elongation) and lower levels of tensile ductility for more constrained samples. Nevertheless, the accumulation of damage each cycle in line with the strain accumulation has been observed previously in pipeline steels and models of void growth developed to cover a variety of constraints $[31,45,46]$. In the same way this data could be used to develop a predicted model for low cycle fatigue behaviour of additively manufactured parts.

\section{Data available statement}

The raw/processed data required to reproduce these findings cannot be shared at this time as the data also forms part of an ongoing study.

\section{Declaration of competing interest}

The authors declare that they have no known competing financial interests or personal relationships that could have appeared to influence the work reported in this paper.

\section{CRediT authorship contribution statement}

Jianguang Bao: Conceptualization, Methodology, Formal analysis, Investigation, Data curation, Writing - original draft, Visualization. Shengchuan Wu: Conceptualization, Methodology, Formal analysis, Writing - review \& editing, Project administration, Funding acquisition. Philip J. Withers: Conceptualization, Formal analysis, Writing - Review \& Editing, Funding acquisition. Zhengkai Wu: Data Curation, 
Investigation, Writing - review \& editing, Visualization. Fei Li: Formal analysis,

Resources. Yanan Fu: Methodology, Investigation. Wei Sun: Conceptualization, Writing

- review \& editing, Supervision, Project administration, Funding acquisition.

\section{Acknowledgements}

Jianguang Bao and Professor Wei Sun would like to acknowledge the China Scholarship Council and the Aviation Industry Corporation of China for the sponsorship of the PhD project for Jianguang Bao. Prof. Shengchuan Wu thanks are also given to the supports from the National Natural Science Foundation of China (11572267). Professor Philip J. Withers acknowledges the European Research Grant (CORREL-CT, 695638) and funding this work was supported by the Henry Royce Institute for Advanced Materials, through EPSRC grants EP/R00661X/1, EP/S019367/1, EP/P025021/1 and EP/P025498/1.

\section{References}

[1] T. DebRoy, T. Mukherjee, J.O. Milewski, J.W. Elmer, B. Ribic, J.J. Blecher, W. Zhang, Scientific, technological and economic issues in metal printing and their solutions, Nat. Mater. 18 (2019) 1026-1032. https://doi.org/10.1038/s41563-019-0408-2.

[2] C.Y. Yap, C.K. Chua, Z.L. Dong, Z.H. Liu, D.Q. Zhang, L.E. Loh, S.L. Sing, Review of selective laser melting: Materials and applications, Appl. Phys. Rev. 2 (2015). https://doi.org/10.1063/1.4935926.

[3] K.N. Amato, S.M. Gaytan, L.E. Murr, E. Martinez, P.W. Shindo, J. Hernandez, S. Collins, F. Medina, Microstructures and mechanical behavior of Inconel 718 fabricated by selective laser melting, Acta $\quad$ Mater. $60 \quad$ (2012)

2229-2239. https://doi.org/https://doi.org/10.1016/j.actamat.2011.12.032.

[4] J.H. Martin, B.D. Yahata, J.M. Hundley, J.A. Mayer, T.A. Schaedler, T.M. Pollock, 3D printing of highstrength aluminium alloys, Nature. 549 (2017) 365-369. https://doi.org/10.1038/nature23894.

[5] M.J. Couper, A.E. Neeson, J.R. Griffiths, CASTING DEFECTS AND THE FATIGUE BEHAVIOUR OF AN ALUMINIUM CASTING ALLOY, Fatigue Fract. Eng. Mater. Struct. (1990). https://doi.org/10.1111/j.1460-2695.1990.tb00594.x.

[6] C.M. Sonsino, J. Ziese, Fatigue strength and applications of cast aluminium alloys with different degrees of porosity, Int. J. Fatigue. (1993). https://doi.org/10.1016/0142-1123(93)90001-7.

[7] B. Skallerud, T. Iveland, G. Härkegård, Fatigue life assessment of aluminum alloys with casting defects, Eng. Fract. Mech. (1993). https://doi.org/10.1016/0013-7944(93)90108-5. 
[8] V.-D. Le, N. Saintier, F. Morel, D. Bellett, P. Osmond, Investigation of the effect of porosity on the high cycle fatigue behaviour of cast Al-Si alloy by X-ray micro-tomography, Int. J. Fatigue. 106 (2018) 24-37. https://doi.org/https://doi.org/10.1016/j.ijfatigue.2017.09.012.

[9] G. Nicoletto, R. Konečná, S. Fintova, Characterization of microshrinkage casting defects of Al-Si alloys by X-ray computed tomography and metallography, Int. J. Fatigue. 41 (2012) 39-46. https://doi.org/10.1016/j.ijfatigue.2012.01.006.

[10] P. Li, P.D. Lee, D.M. Maijer, T.C. Lindley, Quantification of the interaction within defect populations on fatigue behavior in an aluminum alloy, Acta Mater. 57 (2009) 3539-3548. https://doi.org/10.1016/j.actamat.2009.04.008.

[11] J.Y. Buffière, S. Savelli, P.H. Jouneau, E. Maire, R. Fougères, Experimental study of porosity and its relation to fatigue mechanisms of model Al-Si7-MgO.3 cast Al alloys, Mater. Sci. Eng. A. 316 (2001) 115-126. https://doi.org/10.1016/S0921-5093(01)01225-4.

[12] J.N. Domfang Ngnekou, Y. Nadot, G. Henaff, J. Nicolai, W.H. Kan, J.M. Cairney, L. Ridosz, Fatigue properties of AlSi10Mg produced by Additive Layer Manufacturing, Int. J. Fatigue. 119 (2019) 160-172. https://doi.org/10.1016/j.ijfatigue.2018.09.029.

[13] N.O. Larrosa, W. Wang, N. Read, M.H. Loretto, C. Evans, J. Carr, U. Tradowsky, M.M. Attallah, P.J. Withers, Linking microstructure and processing defects to mechanical properties of selectively laser melted AlSi10Mg alloy, Theor. Appl. Fract. Mech. 98 (2018) 123-133. https://doi.org/10.1016/j.tafmec.2018.09.011.

[14] S. Beretta, S. Romano, A comparison of fatigue strength sensitivity to defects for materials manufactured by AM or traditional processes, Int. J. Fatigue. 94 (2017) 178-191. https://doi.org/https://doi.org/10.1016/j.ijfatigue.2016.06.020.

[15] M. Tang, P.C. Pistorius, Oxides, porosity and fatigue performance of AlSi10Mg parts produced by selective laser melting, Int. J. Fatigue. 94 (2017) 192-201. https://doi.org/10.1016/j.ijfatigue.2016.06.002.

[16] I. Serrano-Munoz, J.Y. Buffiere, R. Mokso, C. Verdu, Y. Nadot, Location, location \&size: Defects close to surfaces dominate fatigue crack initiation, Sci. Rep. 7 (2017) 1-9. https://doi.org/10.1038/srep45239.

[17] S. Tammas-Williams, P.J. Withers, I. Todd, P.B. Prangnell, The Influence of Porosity on Fatigue Crack Initiation in Additively Manufactured Titanium Components, Sci. Rep. 7 (2017) 1-13. https://doi.org/10.1038/s41598-017-06504-5.

[18] S. Dezecot, V. Maurel, J.Y. Buffiere, F. Szmytka, A. Koster, 3D characterization and modeling of low cycle fatigue damage mechanisms at high temperature in a cast aluminum alloy, Acta Mater. 123 (2017) 24-34. https://doi.org/10.1016/j.actamat.2016.10.028.

[19] C. Cai, H. Geng, Q. Cui, S. Wang, Z. Zhang, Low cycle fatigue behavior of AlSi10Mg(Cu) alloy at high $\begin{array}{lllll}\text { temperature, } & \text { Mater. } & \text { Charact. } & 145 & \text { (2018) }\end{array}$ https://doi.org/10.1016/j.matchar.2018.09.023.

[20] S. Romano, A. Brandão, J. Gumpinger, M. Gschweitl, S. Beretta, Qualification of AM parts: Extreme value statistics applied to tomographic measurements, Mater. Des. 131 (2017) 32-48. https://doi.org/10.1016/j.matdes.2017.05.091.

[21] P.J. Withers, M. Preuss, Fatigue and Damage in Structural Materials Studied by X-Ray Tomography, Annu. Rev. Mater. Res. 42 (2012) 81-103. https://doi.org/10.1146/annurev-matsci-070511155111.

[22] S.C. Wu, T.Q. Xiao, P.J. Withers, The imaging of failure in structural materials by synchrotron radiation X-ray microtomography, Eng. Fract. Mech. 182 (2017) 127-156. https://doi.org/10.1016/j.engfracmech.2017.07.027.

[23] L. Lecarme, E. Maire, A.K. Kc, C. De Vleeschouwer, L. Jacques, A. Simar, T. Pardoen, Heterogenous void growth revealed by in situ 3-D X-ray microtomography using automatic cavity tracking, Acta Mater. 63 (2014) 130-139. https://doi.org/https://doi.org/10.1016/j.actamat.2013.10.014. 
[24] C. Landron, E. Maire, O. Bouaziz, J. Adrien, L. Lecarme, A. Bareggi, Validation of void growth models using X-ray microtomography characterization of damage in dual phase steels, Acta Mater. 59 (2011) 7564-7573. https://doi.org/10.1016/j.actamat.2011.08.046.

[25] E. Maire, O. Bouaziz, M. Di Michiel, C. Verdu, Initiation and growth of damage in a dual-phase steel observed by X-ray microtomography, Acta Mater. 56 (2008) 4954-4964. https://doi.org/10.1016/j.actamat.2008.06.015.

[26] S.C. Wu, X. Yu, R.Z. Zuo, W.H. Zhang, H.L. Xie, J.Z. Jiang, Porosity, element loss, and strength model on softening behavior of hybrid laser arc welded Al-Zn-Mg-Cu alloy with synchrotron radiation analysis, Weld. J. 92 (2013) 64s-71s.

[27] S. Tammas-Williams, P.J. Withers, I. Todd, P.B. Prangnell, Porosity regrowth during heat treatment of hot isostatically pressed additively manufactured titanium components, Scr. Mater. 122 (2016) 72-76. https://doi.org/10.1016/j.scriptamat.2016.05.002.

[28] S. Siddique, M. Imran, M. Rauer, M. Kaloudis, E. Wycisk, C. Emmelmann, F. Walther, Computed tomography for characterization of fatigue performance of selective laser melted parts, Mater. Des. 83 (2015) 661-669. https://doi.org/10.1016/j.matdes.2015.06.063.

[29] T.P. Chapman, K.M. Kareh, M. Knop, T. Connolley, P.D. Lee, M.A. Azeem, D. Rugg, T.C. Lindley, D. Dye, Characterisation of short fatigue cracks in titanium alloy IMI 834 using X-ray $\begin{array}{lllll}\text { microtomography, } & \text { Acta } & \text { Mater. } & 99 & \text { (2015) }\end{array}$ https://doi.org/https://doi.org/10.1016/j.actamat.2015.07.069.

[30] Y.C. Hung, P.J. Withers, Fibre bridging during high temperature fatigue crack growth in Ti/SiC composites, Acta Mater. 60 (2012) 958-971. https://doi.org/10.1016/j.actamat.2011.10.036.

[31] A.M. Kanvinde, G.G. Deierlein, Cyclic void growth model to assess ductile fracture initiation in structural steels due to ultra low cycle fatigue, J. Eng. Mech. (2007). https://doi.org/10.1061/(ASCE)0733-9399(2007)133:6(701).

[32] S.C. Wu, C. Yu, P.S. Yu, J.Y. Buffière, L. Helfen, Y.N. Fu, Corner fatigue cracking behavior of hybrid laser AA7020 welds by synchrotron X-ray computed microtomography, Mater. Sci. Eng. A. 651 (2016) 604-614. https://doi.org/10.1016/j.msea.2015.11.011.

[33] E. Padilla, V. Jakkali, L. Jiang, N. Chawla, Quantifying the effect of porosity on the evolution of deformation and damage in Sn-based solder joints by X-ray microtomography and microstructure-based finite element modeling, Acta Mater. 60 (2012) 4017-4026. https://doi.org/10.1016/j.actamat.2012.03.048.

[34] Y. Guo, T.L. Burnett, S.A. McDonald, M. Daly, A.H. Sherry, P.J. Withers, 4D Imaging of Void Nucleation, Growth and Coalescence from Large and Small Inclusions in Steel, Growth Coalescence from Large Small Inclusions Steel (November 20, 2019). (2019). https://doi.org/https://dx.doi.org/10.2139/ssrn.3490434.

[35] J.R. Rice, D.M. Tracey, On the ductile enlargement of voids in triaxial stress fields*, J. Mech. Phys. Solids. (1969). https://doi.org/10.1016/0022-5096(69)90033-7.

[36] T. Pardoen, J.W. Hutchinson, An extended model for void growth and coalescence, J. Mech. Phys. Solids. 48 (2000) 2467-2512. https://doi.org/https://doi.org/10.1016/S0022-5096(00)00019-3.

[37] F. Scheyvaerts, P.R. Onck, C. Tekoğlu, T. Pardoen, The growth and coalescence of ellipsoidal voids in plane strain under combined shear and tension, J. Mech. Phys. Solids. 59 (2011) 373-397. https://doi.org/10.1016/j.jmps.2010.10.003.

[38] A. Weck, D.S. Wilkinson, E. Maire, H. Toda, Visualization by X-ray tomography of void growth and coalescence leading to fracture in model materials, Acta Mater. 56 (2008) 2919-2928. https://doi.org/10.1016/j.actamat.2008.02.027.

[39] J. Li, J. Xu, B. Guo, D. Shan, T.G. Langdon, Shear fracture mechanism in micro-tension of an ultrafine-grained pure copper using synchrotron radiation X-ray tomography, Scr. Mater. 132 (2017) 25-29. https://doi.org/https://doi.org/10.1016/j.scriptamat.2017.01.021.

[40] L.M. Brown, J.D. Embury, Proc. 3rd Int. Conf. on Strength of Metals and Alloys, (1973). 
[41] P.F. Thomason, Ductile fracture of metals, Pergamon Press Plc, Ductile Fract. Met. 1990,. (1990) 219.

[42] F. Hannard, T. Pardoen, E. Maire, C. Le Bourlot, R. Mokso, A. Simar, Characterization and micromechanical modelling of microstructural heterogeneity effects on ductile fracture of 6xxx $\begin{array}{lllll}\text { aluminium alloys, } & \text { Acta } & \text { Mater. } & 103 & \text { (2016) 558-572. }\end{array}$ https://doi.org/10.1016/j.actamat.2015.10.008.

[43] D. Lassance, D. Fabrègue, F. Delannay, T. Pardoen, Micromechanics of room and high temperature fracture in 6xxx Al alloys, Prog. Mater. Sci. 52 (2007) 62-129. https://doi.org/10.1016/j.pmatsci.2006.06.001.

[44] H. Kuwamura, K. Yamamoto, Ductile crack as trigger of brittle fracture in steel, J. Struct. Eng. (1997). https://doi.org/10.1061/(ASCE)0733-9445(1997)123:6(729).

[45] J.C.R. Pereira, A.M.P. de Jesus, J. Xavier, J.A.F.O. Correia, L. Susmel, A.A. Fernandes, Low and ultralow-cycle fatigue behavior of X52 piping steel based on theory of critical distances, Int. J. Fatigue. (2020). https://doi.org/10.1016/j.ijfatigue.2020.105482.

[46] J.C.R. Pereira, A.M.P. de Jesus, A.A. Fernandes, A new ultra-low cycle fatigue model applied to the X60 piping steel, Int. J. Fatigue. (2016). https://doi.org/10.1016/j.ijfatigue.2016.08.017. 